\title{
Flavours: the pleasure principle
}

\author{
John Prescott
}

\begin{abstract}
Flavour perception reflects the integration of distinct sensory signals, in particular odours and tastes, primarily through the action of associative learning. This gives rise to sensory interactions derived from the innate properties of tastes. It is argued that while the integration inherent in flavours may have adaptive meaning in terms of food identification, the primary purpose is to provide a hedonic value to the odour and the flavour. Hence, flavours may be seen primarily as units of pleasure that influence our motivation to consume.
\end{abstract}

Keywords: Flavour, Odour, Taste, Sensory integration, Learning, Hedonics

The idea of flavours as the outcome of the integration of tastes, odours and oral somatosensory (tactile) qualities has a long pedigree [1-3]. In recent years, this concept has received support from the identification of the brain's network of neural structures that function together to uniquely encode flavours $[4,5]$. From the perspective of food preferences, too, flavours seem to be fundamental units. This is primarily because at birth (or in the case of salt, shortly thereafter), we are hedonically inflexible when it comes to basic tastes-sweet, sour, salty, bitter and umami. Our likes and dislikes appear to be pre-set as an adaptive mechanism to ensure intake of nutrients (sweetness, saltiness, umami) and avoid toxins or otherwise harmful substances (bitterness, sourness). On the other hand, there is little evidence that odour preferences are other than the result of experience, a process that may begin in the womb [6].

Of course, we can learn to like or dislike odours in isolation-experience with flowers or sewer smells is sufficient. But in the context of eating, we never experience the odours in flavours without accompanying tastes. This has two consequences. The first of these is that the hedonic properties of tastes become attached to the odour through their repeated co-exposure $[7,8]$, an example of a general associative learning process known as evaluative conditioning [9]. In other words, odours paired with sweetness become liked; odours paired with bitterness typically become disliked. The second process, also based on associative learning, reflects the metabolic value of those food ingredients that give rise to tastes

Correspondence: Prescott@taste-matters.org

TasteMatters Research \& Consultancy, Sydney, Australia qualities (e.g. sugar, glutamate) or otherwise have value as nutrients (e.g. fat). Odours paired with metabolic value can become liked even when the taste is unpleasant, which explains how we can develop strong preferences for bitter drinks such as coffee or beer, or 'painful' foods that contain chilli. While these two learning processes are seemingly similar, they can be dissociated by, for example, conditioning liking for an odour paired with a non-nutritive sweetener such as aspartame or alternatively pairing the odour with energy in the form of sugar, but under conditions of satiety, in which case the amount of increased liking is limited [10].

Pairing ingested nutrients with odours has other important consequences, particularly in relation to motivation to consume. Thus, pairing novel odours with glutamate in soup increases liking for those odours, but in addition, exposure to the flavour following conditioning also increased feelings of hunger and increased consumption of the soup, relative to simple repeated exposure to the soup [11]. This suggests a mechanism for the development of food 'wanting, a distinct construct from 'liking' that has been explored in terms of both distinct neural and motivational substrates [12,13]. Wanting reflects a drive to consume, the effects of which can be observed in eating that is independent of energy needs. In particular, wanting can be triggered by sensory cues-odours, visual or auditory cuesthat have been associated with nutrient learning. Examples of this can be found in research showing that consumption of a food in response to cues can occur even after consuming the same food to satiation [14]. As such, there is obvious relevance to our understanding of the aetiology of obesity. 
Research evidence for integration of tastes, odours and somatosensory inputs into flavours comes from a variety of sources, including cell recordings in animals [15], fMRI studies of neural activation in humans [16] and psychophysical studies of odour/taste interactions following repeated co-exposure [17]. An important question, though, relates to the adaptive significance of the 'construction' of flavours-why do discrete neural circuits, for example, represent flavours rather than simply odours and tastes separately?

Integration of information from physiologically distinct sensory modalities appears to be a general property of the mammalian nervous system [18]. Moreover, we know from studies of multi-modal sensory integration in other systems (vision, hearing, touch) that such integration, even when it supplies redundant information, aids in the detection and recognition of objects, particularly in those cases where a single sensory modality fails to supply all the necessary information for such recognition [19]. From a theoretical perspective, Gibson [20] has argued that the primary purpose of perception is to seek out objects in our environment, particularly those that are biologically important. As such, the physiological origin of sensations is less important than that these sensations can be used in object identification. Because of its adaptive significance, flavour perception is perhaps the most prominent example of this notion.

But this explanation does not provide a complete understanding of the significance of flavours. While it can be argued that it is taste and odour together that allow us to recognize pear as a pear, in practice, once it is familiar, the pear odour is sufficient. In a world without taste, trial and error would allow one to distinguish pears from apples and could even tell you whether or not pears were safe to eat. However, through learning, the integration of odours with tastes attaches additional meaning to the odour that is primarily hedonic. The pear flavour that is not bitter, not too sour, and quite sweet provides pleasure in eating. In other words, we are motivated to consume it because of its prior associations with the pleasure of sweet taste and the calories that the sweetness, and subsequently, the pear odour signals. And, of course, this occurs even prior to eating: the odour of the pear itself becomes pleasant.

The perceptual consequences of odour/taste integration can be interpreted in the same way. The wellknown phenomena of food odours being described in terms of tastes-sweet smell of vanilla or the sour smell of vinegar-are consequences of odour/taste integration and apparently independent from the hedonic changes $[8,21]$. But these perceptual qualities also have hedonic consequences-sweet smelling odours are pleasant and this quality may in itself motivate consumption even if we cannot identify the actual odour or its source. There is even evidence suggesting that such odours activate the same reward pathways as tasted sweetness [22]. Conversely, a bitter or sour odour is likely to elicit rejection, especially if we cannot recognize the odour. As such, these perceptual changes to odours may help compensate for the fact that odour identification is particularly difficult even for common foods [23].

The key purpose of sensory integration is not that it aids identification per se (although it might), but rather that it confers a hedonic valence (positive or negative) on to the odour, which crucially is the defining characteristic of the food. Thus, flavours can be most accurately seen as objects constructed for their hedonic qualities. Initial 'gut' responses to foods are almost always hedonic, and this naturally precedes accepting or rejecting the food. Thus, what we perceive when we sit down to dinner are, thankfully, integrated hedonically positive perceptionsspaghetti al pomodoro and a nice Chianti-rather than a collection of independent, hedonically diverse tastes, odours and textures.

\section{Competing interests}

The author declares that he has no competing interests.

Received: 2 December 2014 Accepted: 2 December 2014 Published: 16 February 2015

\section{References}

1. Brillat-Savarin J-A: The Physiology of Taste. 1994th edition. London: Penguin Books; 1825

2. Prescott J: Taste Matters. Why We Like the Foods We Do. London: Reaktion Books; 2012

3. Prescott J, Stevenson RJ (2015) Chemosensory integration and the perception of flavor. In: Doty RL (ed) Handbook of Olfaction \& Gustation, 3rd edn. Modern Perspectives John Wiley \& Sons, Wiley, pp 1009-1028

4. Small DM, Prescott J: Odor/taste integration and the perception of flavor. Exp Brain Res 2005, 166:345-357.

5. Small DM: Crossmodal integration: insights from the chemical senses. Trends Neurosci 2004, 27(3):120-123.

6. Mennella JA, Jagnow CP, Beauchamp GK: Prenatal and postnatal flavor learning by human infants. Pediatrics 2001, 107(6):E88.

7. Zellner DA, Rozin P, Aron M, Kulish C: Conditioned enhancement of human's liking for flavor by pairing with sweetness. Learn Motiv 1983, 14:338-350.

8. Yeomans MR, Mobini S, Elliman TD, Walker HC, Stevenson RJ: Hedonic and sensory characteristics of odors conditioned by pairing with tastants in humans. J Exp Psychol Anim Behav Process 2006, 32(3):215-228.

9. De Houwer J, Thomas S, Baeyens F: Associative learning of likes and dislikes: a review of 25 years of research on human evaluative conditioning. Psychol Bull 2001, 127(6):853-869.

10. Mobini S, Chambers LC, Yeomans MR: Effects of hunger state on flavour pleasantness conditioning at home: flavour-nutrient learning vs. flavourflavour learning. Appetite 2007, 48:20-28.

11. Yeomans MR, Gould NJ, Mobini S, Prescott J: Acquired flavor acceptance and intake facilitated by monosodium glutamate in humans. Physiol Behav 2008, 93:958-966.

12. Castro DC, Berridge KC: Advances in the neurobiological bases for food 'liking' versus 'wanting'. Physiol Behav 2014, 136:22-30.

13. Garcia-Burgos D, Zamora MC: Exploring the hedonic and incentive properties in preferences for bitter foods via self-reports, facial expressions and instrumental behaviours. Food Qual Pref 2015, 39:73-81.

14. Ferriday D, Brunstrom JM: How does food-cue exposure lead to larger meal sizes? Br J Nutr 2008, 100:1325-1332.

15. Rolls ET, Bayliss LL: Gustatory, olfactory, and visual convergence within the primate orbitofrontal cortex. J Neurosci 1994, 14(9):5437-5452. 
16. Small DM, Voss J, Mak E, Simmons KB, Parrish T, Gitelman D: Experiencedependent neural integration of taste and smell in the human brain. J Neurophysiol 2004, 92:1892-1903.

17. Stevenson RJ, Prescott J, Boakes RA: The acquisition of taste properties by odors. Learn Motiv 1995, 26:1-23.

18. Stein BE, Meredith MA: The Merging of the Senses. Cambridge, Mass: The MIT Press; 1993.

19. Calvert GA, Brammer MJ, Bullmore ET, Campbell R, Iversen SD, David AS: Response amplification in sensory-specific cortices during crossmodal binding. Neuroreport 1999, 10:2619-2623.

20. Gibson Jj: The Senses Considered as Perceptual Systems. Boston: Houghton Mifflin Company; 1966.

21. Stevenson RJ, Prescott J, Boakes RA: Confusing tastes and smells: how odors can influence the perception of sweet and sour tastes. Chem Senses 1999, 24:627-635.

22. Prescott J, Wilkie J: Pain tolerance selectively increased by a sweet-smelling odor. Psychol Sci 2007, 18(4):308-311.

23. Lawless $\mathrm{H}$, Engen $\mathrm{T}$ : Associations to odors: interference, mnemonics, and verbal labeling. J Exp Psychol Hum Learn 1977, 3(1):52-59.

doi:10.1186/2044-7248-4-15

Cite this article as: Prescott: Flavours: the pleasure principle. Flavour 2015 4:15.

\section{Submit your next manuscript to BioMed Central and take full advantage of:}

- Convenient online submission

- Thorough peer review

- No space constraints or color figure charges

- Immediate publication on acceptance

- Inclusion in PubMed, CAS, Scopus and Google Scholar

- Research which is freely available for redistribution 